\title{
Correlation between tobacco control policies, consumption of rolled tobacco and e-cigarettes, and intention to quit conventional tobacco, in Europe
}

\author{
Cristina Lidón-Moyano, ${ }^{1}$ Juan Carlos Martín-Sánchez, ${ }^{1}$ Patrick Saliba, ${ }^{1}$ \\ Jan Graffelman, ${ }^{2}$ Jose M Martínez-Sánchez ${ }^{1,3,4}$
}

${ }^{1}$ Biostatistics Unit, Department of Basic Sciences, Universitat Internacional de Catalunya, Sant Cugat del Vallès, Barcelona, Spain

${ }^{2}$ Department of Statistics and Operations Research,

Universitat Politècnica de Catalunya, Barcelona, Spain

${ }^{3}$ Tobacco Control Unit, Cancer Prevention and Control Programme, Catalan Institute of Oncology-ICO, L'Hospitalet de Llobregat, Barcelona, Spain

${ }^{4}$ Cancer Control and Prevention Group, Bellvitge Biomedical Research InstituteIDIBELL, L'Hospitalet de Llobregat, Barcelona, Spain

\section{Correspondence to}

Dr Jose M Martínez-Sánchez, Biostatistics Unit, Department of Basic Sciences, Universitat Internacional de Catalunya, Sant Cugat del Vallés, Barcelona, Spain; jmmartinez@uic.es

Received 25 May 2015 Accepted 25 January 2016

\footnotetext{
To cite: Lidón-Moyano C, Martín-Sánchez JC, Saliba P, et al. Tob Control Published Online First: [please include Day Month Year]

doi:10.1136/tobaccocontrol2015-052482
}

\section{ABSTRACT}

Objective To analyse the correlation between the implementation of tobacco control policies and tobacco consumption, particularly rolling tobacco, electronic cigarettes (e-cigarettes) users and the intent to quit smoking in 27 countries of the European Union.

Design Ecological study with the country as the unit of analysis.

Data sources We used the data from tobacco control activities, measured by the Tobacco Control Scale (TCS), in 27 European countries, in 2010, and the prevalence of tobacco consumption data from the Eurobarometer of 2012.

Analysis Spearman correlation coefficients $\left(r_{\mathrm{sp}}\right)$ and their $95 \% \mathrm{Cls}$.

Results There was a negative correlation between TCS and prevalence of smoking $\left(r_{s p}=-0.41 ; 95 \% \mathrm{Cl}-0.67\right.$ to -0.07$)$. We also found a negative correlation $\left(r_{\mathrm{sp}}=-0.31\right)$ between TCS and the prevalence of ever e-cigarette users, but it was not statistically significant. Among former cigarette smokers, there was a positive and statistically significant correlation between TCS and the consumption of hand-rolled tobacco $\left(r_{\mathrm{sp}}=0.46 ; 95 \%\right.$ $\mathrm{Cl} 0.06$ to 0.70 ). We observed a similar correlation between TCS and other tobacco products (cigars and pipe) among former cigarette smokers. There was a significant positive correlation between TCS and intent to quit smoking in the past 12 months $\left(r_{s p}=0.66 ; 95 \% \mathrm{Cl}\right.$ 0.36 to 0.87 ).

Conclusions The level of smoke-free legislation among European countries is correlated with a decrease in the prevalence of smoking of conventional cigarettes and an increase in the intent to quit smoking within the past 12 months. However, the consumption of other tobacco products, particularly hand-rolled tobacco, is positively correlated with TCS among former cigarette smokers. Therefore, tobacco control policies should also consider other tobacco products, such as rolling tobacco, cigars and pipes.

\section{INTRODUCTION}

Tobacco is the single greatest cause of preventable death in the world. ${ }^{1}$ Several countries have implemented smoke-free legislation focused on the reduction of secondhand smoke exposure (SHS). However, the adoption of tobacco control policies focuses (eg, the increase of price) mainly on manufactured cigarettes and often neglects other tobacco products, such as hand-rolled tobacco. ${ }^{2}$ In fact, the consumption of hand-rolled tobacco has increased in the past few years ${ }^{3-5}$ and hand-rolled cigarettes were smoked by one in three European smokers in
2011. ${ }^{6}$ Moreover, the use of electronic cigarettes (e-cigarettes) has rapidly increased worldwide.

A previous study conducted in Europe ${ }^{8}$ showed a negative relationship between tobacco control policies and the smoking of conventional cigarettes as well as exposure to SHS in workplaces. Moreover, the tobacco control policies in Europe were not correlated with an increase of tobacco consumption in private venues ${ }^{9}$ and were correlated with a rise in the prevalence of smoke-free homes. ${ }^{10}$ However, there is a lack of evidence, to the best of our knowledge, about the impact of tobacco control bans on the consumption of other tobacco products, such as rolling tobacco and the use of e-cigarettes. The objective of this study is to analyse the correlation between the implementation of tobacco control policies and tobacco consumption, particularly rolling tobacco, e-cigarettes users and the intent to quit smoking in 27 countries of the European Union (EU).

\section{METHODS}

This is an ecological study with each country as the unit of analysis. We used data from tobacco control activities, measured by the Tobacco Control Scale $(\mathrm{TCS})^{11}$ proposed by Joossens and Raw, ${ }^{12}$ in 27 European countries, in 2010, and the data of the prevalence of tobacco consumption from the Eurobarometer of 2012. ${ }^{13}$ The Special Eurobarometer $385^{13}$ is a cross-sectional study $(n=26751)$ conducted between February and March of 2012 among the adult population (>15 years old).

We obtained the following variables through different questions from the Eurobarometer:

Information regarding cigarette consumption obtained through the specific question: 'Regarding smoking cigarettes, cigars or a pipe, which of the following applies to you?'. In which the possible answers were: 'You currently smoke'; 'You used to smoke but you have stopped' and 'You have never smoked', and were measured by way of the prevalence of smoking. We defined current smokers as people who answered 'You currently smoke'.

Additionally, we obtained information on other tobacco product consumption (boxed cigarettes, hand-rolled cigarettes, cigars and pipe) through the question: 'How often do/did you use the following tobacco products?'. The answers to this question were grouped as regular users (daily, weekly or monthly) and non-regular users, and differentiating between smokers and former cigarette smokers. 
Eurobarometer also provided information on other ways of smoking through the question: 'Have you ever tried any of the following products? Water pipe, oral tobacco, chewing or nasal tobacco, e-cigarettes, and smokeless cigarettes', and the answers to this question were grouped as either 'Yes' or 'No'. This question was given to the whole population (smokers, former smokers and non-smokers).

Previous intent to quit smoking was measured by way of the prevalence of the answer 'Yes, in the past 12 months' from the question: 'Have you ever tried to quit smoking?'.

Self-reported exposure to SHS at work among non-smokers was obtained asking the question: 'How often are you exposed to tobacco smoke indoors at your workplace?', where the answers were grouped as either exposed or non-exposed.

We used the TCS from 2010 to measure the level of the six most cost-effective tobacco control policies in European countries in 2010. ${ }^{12}$

We analysed the correlation between TCS score (and their six policies) and the different rates of prevalence (eg, cigarette consumption, use of other tobacco products, previous intent to quit, etc) by calculating Spearman correlation coefficients $\left(r_{\mathrm{sp}}\right)$ and their 95\% confidence intervals (CIs).

\section{RESULTS}

There was an inverse and statistically significant correlation between TCS and prevalence of smoking of conventional cigarettes (table 1). The correlation between TCS and intent to quit smoking within the past 12 months was positive and statistically significant $\left(\mathrm{r}_{\mathrm{sp}}=0.66 ; 95 \% \mathrm{CI} 0.36\right.$ to 0.87$)$. The correlation between TCS and SHS exposure at work was negative $\left(\mathrm{r}_{\mathrm{sp}}=\right.$ $-0.59 ; 95 \% \mathrm{CI}-0.81$ to -0.22$)$.

Among current smokers, there were positive correlations, only statistically significant in the case of pipe smoking $\left(\mathrm{r}_{\mathrm{sp}}\right.$ $=0.49 ; 95 \%$ CI 0.13 to 0.73 ), between TCS and consumption of other tobacco products. Among former cigarette smokers, there were positive and statistically significant correlations between TCS and other tobacco products with the exception of boxed cigarettes (table 1).

We found statistically significant negative correlation between TCS and the prevalence of having ever tried a water pipe $\left(\mathrm{r}_{\mathrm{sp}}=\right.$ $-0.39 ; 95 \%$ CI -0.62 to -0.06$)$. The correlation of TCS with the prevalence of ever e-cigarette use was not statistically significant $\left(\mathrm{r}_{\mathrm{sp}}=-0.31 ; 95 \% \mathrm{CI}-0.61\right.$ to 0.03$)$.

\section{DISCUSSION}

Our results, at the ecological level, show that there is an inverse correlation between the levels of tobacco control policies implemented across European countries and the consumption of conventional cigarettes and exposure to SHS at work. These results are in agreement with previous ecological, ${ }^{8} 9$ multilevel $^{10}$ and individual studies. ${ }^{14}$ However, there is positive correlation between the different levels of tobacco control policies implemented among countries and the consumption of other tobacco products among former cigarette smokers, particularly hand-rolled tobacco. This correlation should be interpreted with caution because the question of the Eurobarometer does not permit the restriction of this analysis to former cigarette smokers who had quit smoking cigarette after the implementation of tobacco control policies. Therefore, the prevalence of other tobacco products, including hand-rolled tobacco, among former cigarette smokers cannot be guaranteed to be a consequence of the six tobacco control policies measured in the TCS. However, previous studies showed an increase of daily consumption, per capita, of hand-rolled tobacco and market share of rolling tobacco in the past decade. ${ }^{3} 15$

Thereby, our results could be backing the hypothesis of a switch of smokers to cheaper tobacco products, such as hand rolled cigarettes, because the tobacco control policies, particularly increasing of prices, are focused on conventional cigarettes. Previous studies showed that daily per capita consumption of hand-rolled cigarettes increased on average by $14.1 \%$ per year from 1991 to 2012 in Spain, while the consumption of manufactured cigarettes decreased by $3 \%$ on average. ${ }^{3}$ A similar pattern has been found in other countries such as Canada, the USA, the UK, Australia ${ }^{4}$ and New Zealand. ${ }^{5}$ These changes in the consumption of tobacco could also be due to the belief that this tobacco product is healthier than conventional manufactured cigarettes. ${ }^{16}$

Furthermore, price increase is consistently reported as one of the most effective means of reducing tobacco consumption; ${ }^{17}$ nevertheless, the real prices of the cheapest cigarettes have remained largely unchanged since 2006, and the gap between the cheapest and the most expensive cigarettes has been widened. ${ }^{18}$ In fact, hand-rolled cigarettes were taxed at half the level of manufactured cigarettes in $2014 .{ }^{18}$ Bearing this in mind, there is a need to equalise the prices of all tobacco products by applying the same taxing level as, indeed, is recommended by the article 6 of the Framework Convention on Tobacco Control. ${ }^{19}$

Regarding the consumption of e-cigarettes, the public awareness has grown substantially in recent years. ${ }^{20}$ However, we observed unexpected negative correlation between TCS and the prevalence of having ever tried e-cigarettes, although it was not statistically significant. This result could be due to the fact that the countries with larger TCS are more active in tobacco control and therefore may have prevented the widespread use of the e-cigarettes by, for instance, better consumer information.

We found a positive correlation between TCS and the previous intent to quit smoking (in the past 12 months). This correlation could underestimate the real correlation between TCS and intention to quit because the question of Eurobarometer measured only the previous intention to quit and not the current intention. However, the mean score for Europe in the policies of the treatment to help quit smoking was very low (5.11 up to $10)$ in comparison with other policies. This could mean that, although the smokers may have the intention to quit, they may not receive the help needed to succeed.

The main limitation of this study derives from its ecological design, which yields to the fact that no information about the intensity of association at individual level can be inferred. Moreover, there are some studies showing that the main EU survey generates estimates that are in some cases widely discrepant from more substantive national sources and does not provide age or gender-specific data by country. ${ }^{21}$ In addition, the 2-year gap between the measure of TCS and the Eurobarometer survey does not allow detecting the effect of measures adopted between 2010 and 2012. Nevertheless, the design of the Eurobarometer was the same for all countries, increasing comparability across countries at an ecological level, and the sample size was satisfactorily large and representative by country, and the interviews were face-to-face. In addition, individual studies backing our results exist. ${ }^{22} 23$

In conclusion, our results suggest the need to revise the current legislation, particularly increasing the prices, in order to consider all tobacco products and not only conventional cigarettes. 
Table 1 Spearman correlation coefficients $\left(r_{\mathrm{sp}}\right)$ between TCS (and the six policies of TCS) and prevalence of smoking, prevalence of consumption of other tobacco products (among smokers and former cigarette smokers), prevalence of the intent to quit smoking in the past 12 months and prevalence of self-reported to SHS exposure at work

\begin{tabular}{|c|c|c|c|c|c|c|c|}
\hline & TCS & Price & Public place bans & Public information campaigns & Advertising bans & Health warnings & Treatment \\
\hline \multicolumn{8}{|c|}{ Current cigarette consumption } \\
\hline Smoking cigarettes & $-0.41(-0.67 \text { to }-0.07)^{*}$ & $-0.09(-0.44$ to 0.28$)$ & $-0.35(-0.63$ to 0.07$)$ & $-0.36(-0.63$ to -0.03$)$ & $-0.17(-0.56$ to 0.23$)$ & $0.03(-0.3$ to 0.36$)$ & $-0.47(-0.75 \text { to }-0.08)^{*}$ \\
\hline \multicolumn{8}{|c|}{ Other tobacco products (smokers) } \\
\hline Boxed cigarettes & $-0.30(-0.64$ to 0.11$)$ & $-0.19(-0.55$ to 0.25$)$ & $-0.26(-0.60$ to 0.14$)$ & $-0.54(-0.76 \text { to }-0.22)^{*}$ & $0.04(-0.31$ to 0.38$)$ & $-0.12(-0.52$ to 0.34$)$ & $-0.33(-0.64$ to 0.08$)$ \\
\hline Hand-rolled cigarettes & $0.27(-0.11$ to 0.60$)$ & $0.14(-0.26$ to 0.51$)$ & $0.32(-0.06$ to 0.62$)$ & $0.46(0.12 \text { to } 0.72)^{*}$ & $-0.09(-0.44$ to 0.31$)$ & $0.15(-0.35$ to 0.54$)$ & $0.07(-0.37$ to 0.47$)$ \\
\hline Cigars & $0.28(-0.10$ to 0.62$)$ & $-0.09(-0.49$ to 0.32$)$ & $0.41(0.06 \text { to } 0.72)^{*}$ & $0.39(0.06 \text { to } 0.65)^{*}$ & $0.16(-0.22$ to 0.52$)$ & $0.06(-0.36$ to 0.46$)$ & $0.15(-0.24$ to 0.53$)$ \\
\hline Pipe & $0.49(0.13 \text { to } 0.73)^{*}$ & $0.12(-0.25$ to 0.44$)$ & $0.52(0.10 \text { to } 0.81)^{*}$ & 0.41 (0.05 to 0.68$)$ & $0.15(-0.31$ to 0.61$)$ & $-0.01(-0.01$ to 0.30$)$ & $0.31(-0.10$ to 0.62$)$ \\
\hline \multicolumn{8}{|c|}{ Other tobacco products (former cigarette smokers) } \\
\hline Boxed cigarettes & $-0.04(-0.41$ to 0.37$)$ & $0.10(-0.30$ to 0.45$)$ & $-0.12(-0.51$ to 0.29$)$ & $-0.07(-0.44$ to 0.30$)$ & $0.08(-0.36$ to 0.45$)$ & $-0.04(-0.04$ to 0.37$)$ & $-0.22(-0.63$ to 0.17$)$ \\
\hline Hand-rolled cigarettes & $0.46(0.06 \text { to } 0.70)^{*}$ & $0.14(-0.28$ to 0.53$)$ & $0.51(0.11 \text { to } 0.77)^{*}$ & $0.65(0.40 \text { to } 0.78)^{* *}$ & $0.21(-0.18$ to 0.60$)$ & $0.19(-0.33$ to 0.59$)$ & $0.35(-0.08$ to 0.69$)$ \\
\hline Cigars & $0.41(0.08 \text { to } 0.66)^{*}$ & $0.0007(-0.41$ to 0.39$)$ & $0.41(0.05 \text { to } 0.68)^{*}$ & $0.70(0.47 \text { to } 0.81)^{* *}$ & $0.25(-0.12$ to 0.56$)$ & $0.19(-0.27$ to 0.57$)$ & $0.34(-0.08$ to 0.68$)$ \\
\hline Pipe & $0.41(0.03 \text { to } 0.66)^{*}$ & $-0.01(-0.37$ to 0.35$)$ & $0.44(0.01 \text { to } 0.70)^{*}$ & $0.64(0.34 \text { to } 0.81)^{* *}$ & $0.25(-0.19$ to 0.61$)$ & $0.09(-0.32$ to 0.46$)$ & $0.29(-0.11$ to 0.63$)$ \\
\hline \multicolumn{8}{|c|}{ Other ways of smoking (all populations: smokers, former cigarette smokers and non-smokers) } \\
\hline Water pipe & $-0.39(-0.62 \text { to }-0.06)^{*}$ & $-0.42(-0.71 \text { to }-0.02)^{*}$ & $-0.23(-0.61$ to 0.20$)$ & $-0.1(-0.46$ to 0.25$)$ & $-0.03(-0.44$ to 0.36$)$ & $-0.18(-0.54$ to 0.26$)$ & $-0.16(-0.54$ to 0.25$)$ \\
\hline Oral tobacco & $-0.01(-0.47$ to 0.40$)$ & $-0.19(-0.54$ to 0.25$)$ & $0.06(-0.37$ to 0.47$)$ & $0.13(-0.29$ to 0.48$)$ & $0.03(-0.45$ to 0.52$)$ & $-0.01(-0.32$ to 0.32$)$ & $0.13(-0.24$ to 0.51$)$ \\
\hline E-cigarettes & $-0.31(-0.61$ to 0.03$)$ & $-0.07(-0.44$ to 0.30$)$ & $-0.4(-0.70 \text { to }-0.04)^{*}$ & $-0.14(-0.54$ to 0.29$)$ & $-0.04(-0.44$ to 0.35$)$ & $0.04(-0.38$ to 0.41$)$ & $-0.05(-0.47$ to 0.41$)$ \\
\hline Smokeless cigarettes & $0.12(-0.31$ to 0.52$)$ & $-0.27(-0.64$ to 0.13$)$ & $0.23(-0.16$ to 0.59$)$ & $0.13(-0.28$ to 0.50$)$ & $0.3(-0.13$ to 0.66$)$ & $0.02(-0.35$ to 0.40$)$ & $0.23(-0.22$ to 0.60$)$ \\
\hline \multicolumn{8}{|l|}{ Intent to quit smoking } \\
\hline Past 12 months & $0.66(0.36 \text { to } 0.87)^{* *}$ & $0.39(-0.01 \text { to } 0.70)^{*}$ & $0.52(0.14 \text { to } 0.92)^{*}$ & $0.59(0.30 \text { to } 0.78)^{*}$ & $0.40(-0.04 \text { to } 0.73)^{*}$ & $0.48(0.17 \text { to } 0.72)^{*}$ & $0.45(0.08 \text { to } 0.74)^{*}$ \\
\hline \multicolumn{8}{|l|}{ Exposure to SHS at work } \\
\hline & $-0.59(-0.81 \text { to }-0.22)^{*}$ & $-0.19(-0.59$ to 0.23$)$ & $-0.67(-0.85 \text { to } 0.35)^{* *}$ & $-0.64(-0.84 \text { to }-0.35)^{*}$ & $-0.42(-0.72 \text { to }-0.007)^{*}$ & $-0.15(-0.54$ to 0.30$)$ & $-0.37(-0.70$ to 0.03$)$ \\
\hline
\end{tabular}

TCS, Tobacco Control Scale (maximum 100 points) quantifies the full implementation of tobacco control policies at country level and collects information about of the six most cost-effective tobacco control policies. Price: price increases through higher taxes on tobacco products (maximum 30 points); Public place bans: bans/restrictions on smoking in public and work places (maximum 22 points); Public information campaign spending: better consumer information including public information

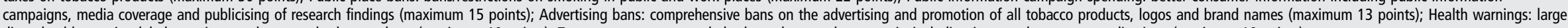
direct health warning labels on cigarette boxes and other products (maximum 10 points); Treatment: treatment to help dependent smokers to quit, including increased access to medications (maximum 10 points).

${ }^{*} p<0.05 ;{ }^{* *} p<0.001$.

SHS, secondhand smoke exposure. 


\section{What this paper adds}

- There is positive correlation between the different levels of tobacco control policies implemented among European countries and the consumption of other tobacco products among former cigarette smokers, particularly hand-rolled tobacco.

- There is an indirect, but not statistically significant, correlation between the prevalence of ever e-cigarette use and the levels of tobacco control policies implemented in Europe.

- The level of smoke-free legislation among European countries is correlated with a decrease in the prevalence of smoking of conventional cigarettes and an increase in the previous intent to quit smoking (in the past months).

Contributors JMM-S conceived the study. CL-M collected the data, prepared the database and analysed the data. CL-M drafted the manuscript, which was critically revised by JMM-S. All the authors contributed substantially to the interpretation of the data and to revising the manuscript. All the authors approved its final version.

Funding This project was funded by the Instituto de Salud Carlos III, Government of Spain (RTICC, RD12/0036/0053 and PI12/01114) and by the Ministry of Universities and Research, Government of Catalonia (grant 2009SGR192) and cofunded by ISCIII-Subdirección General de Evaluación and by FEDER funds/ European Regional Development Fund (ERDF)- a way to build Europe-

Competing interests None declared.

Provenance and peer review Not commissioned; externally peer reviewed.

\section{REFERENCES}

1 World Health Organization. WHO report on the global tobacco epidemic, 2013 Enforcing bans on tobacco advertising, promotion and sponsorship. 2013. http:// apps.who.int/iris/bitstream/10665/85381/1/WHO_NMH_PND_13.2_eng.pdf (accessed 28 Sep 2015).

2 Prignot JJ, Sasco AJ, Poulet E, et al. Alternative forms of tobacco use. Int J Tuberc Lung Dis 2008;12:718-27.

3 Fu M, Martinez-Sanchez JM, Cleries R, et al. Opposite trends in the consumption of manufactured and roll-your-own cigarettes in Spain (1991-2020). BMJ Open 2014:4:e006552.

4 Young $\mathrm{D}$, Yong $\mathrm{HH}$, Borland $\mathrm{R}$, et al. Trends in roll-your-own smoking: findings from the ITC Four-Country Survey (2002-2008). J Environ Public Health 2012;2012:406283.
5 Young D, Wilson N, Borland R, et al. Prevalence, correlates of, and reasons for using roll-your-own tobacco in a high RYO use country: findings from the ITC New Zealand survey. Nicotine Tob Res 2010;12:1089-98.

6 Ash fact sheet. Tobacco policy and the European Union. 2011. http://ash.org.uk/ files/documents/ASH_125.pdf (accessed 28 Sep 2015).

7 Grana R, Benowitz N, Glantz S. Response to letter regarding article, "Electronic cigarettes: a scientific review". Circulation 2015;131:e342.

8 Martínez-Sánchez JM, Fernández E, Fu M, et al. Smoking behavior, involuntary smoking, attitudes towards smoke-free legislations and tobacco control activities in the European Union. PLOS ONE 2010;5:e13881.

9 Martinez-Sanchez JM, Blanch C, Fu M, et al. Do smoke-free policies in work and public places increase smoking in private venues? Tob Control 2014; 23:204-7.

10 Ferketich AK, Lugo A, La Vecchia C, et al. Relation between national-level tobacco control policies and individual-level voluntary home smoking bans in Europe. Tob Control 2016;25:60-5

11 Joossens L, Raw M. The Tobacco Control Scale 2010 in Europe. Brussels: Association of the European Cancer Leagues; http://www.ensp.org/node/576 (accessed 28 Sep 2015).

12 Joossens L, Raw M. The Tobacco Control Scale: a new scale to measure country activity. Tob Control 2006;15:247-53.

13 TNS Opinion \& Social. Special Eurobarometer 385-Attitudes of Europeans towards Tobacco. http://ec.europa.eu/health/tobacco/docs/eurobaro_attitudes_towards_ tobacco_2012_en.pdf (accessed 28 Sep 2015).

14 IARC. Evaluating the Effectiveness of Smoke-free Policies. 2009;13. http://www.iarc. fr/en/publications/pdfs-online/prev/handbook13/handbook13.pdf (accessed 28 Sep 2015).

15 López-Nicolás Á, Cobacho MB, Fernández E. The Spanish tobacco tax loopholes and their consequences. Tob Control 2013;22:e21-4.

16 O'Connor RJ, McNeill A, Borland R, et al. Smokers' beliefs about the relative safety of other tobacco products: findings from the ITC collaboration. Nicotine Tob Res 2007;9:1033-42.

17 The wold Bank: Tobacco. http://www.worldbank.org/en/topic/health/brief/tobacco (accessed 28 Sep 2015).

18 Gilmore AB, Tavakoly B, Hiscock $R$, et al. Smoking patterns in Great Britain: the rise of cheap cigarette brands and roll your own (RYO) tobacco. J Public Health (Oxf) 2015;37:78-88

19 WHO. WHO FRAMEWORK CONVENTION ON TOBACCO CONTROL. http:// whqlibdoc. who.int/publications/2003/9241591013.pdf?ua=1 (accessed 28 Sep 2015).

20 King BA, Alam S, Promoff G, et al. Awareness and ever-use of electronic cigarettes among U.S. adults, 2010-2011. Nicotine Tob Res 2013;15: 1623-7.

21 Bogdanovica I, Godfrey F, McNeill A, et al. Smoking prevalence in the European Union: a comparison of national and transnational prevalence survey methods and results. Tob Control 2011:20:e4

22 Schoretsanitia S, Filippidisa FT, Vardavas $\mathrm{Cl}$, et al. 5-Year trends in the intention to quit smoking amidst the economic crisis and after recently implemented tobacco control measures in Greece. Addict Behav 2014;39:140-5.

23 Gallus S, Spizzichino L, Lugo A, et al. Sales of different tobacco products in Italy, 2004-2012. Prev Med 2013;56:422-3. 


\section{Correlation between tobacco control policies, consumption of rolled tobacco and e-cigarettes, and intention to quit conventional tobacco, in Europe}

Cristina Lidón-Moyano, Juan Carlos Martín-Sánchez, Patrick Saliba, Jan Graffelman and Jose M Martínez-Sánchez

Tob Control published online February 17, 2016

Updated information and services can be found at: http://tobaccocontrol.bmj.com/content/early/2016/02/17/tobaccocont rol-2015-052482

\section{These include:}

References This article cites 15 articles, 9 of which you can access for free at: http://tobaccocontrol.bmj.com/content/early/2016/02/17/tobaccocont rol-2015-052482\#BIBL $\begin{array}{cl}\text { Email alerting } & \text { Receive free email alerts when new articles cite this article. Sign up in the } \\ \text { box at the top right corner of the online article. }\end{array}$ service

\section{Notes}

To request permissions go to:

http://group.bmj.com/group/rights-licensing/permissions

To order reprints go to:

http://journals.bmj.com/cgi/reprintform

To subscribe to BMJ go to:

http://group.bmj.com/subscribe/ 